\title{
New palaeoscolecidan worms from theLower Cambrian: Sirius Passet, Latham Shale, and Kinzers Shale
}

Simon Conway Morris and John S. Peel

Acta Palaeontologica Polonica 55 (1), 2010: 141-156 doi: http://dx.doi.org/10.4202/app.2009.0058

Palaeoscolecidan worms are an important component of many Lower Palaeozoic marine assemblages, with notable occurrences in a number of Burgess Shale-type Fossil-Lagerstätten. In addition to material from the lower Cambrian Kinzers Formation and Latham Shale, we also describe two new palaeoscolecidan taxa from the lower Cambrian Sirius Passet Fossil-Lagerstätte of North Greenland: Chalazoscolex pharkus gen. et sp. nov and Xystoscolex boreogyrus gen. et sp. nov. These palaeoscolecidans appear to be the oldest known (Cambrian Series 2, Stage 3) soft-bodied examples, being somewhat older than the diverse assemblages from the Chengjiang Fossil-Lagerstätte of China. In the Sirius Passet taxa the body is composed of a spinose introvert (or proboscis), trunk with ornamentation that includes regions bearing cuticular ridges and sclerites, and a caudal zone with prominent circles of sclerites. The taxa are evidently quite closely related; generic differentiation is based on degree of trunk ornamentation, details of introvert structure and nature of the caudal region. The worms were probably infaunal or semi-epifaunal; gut contents suggest that at least X. boreogyrus may have preyed on the arthropod Isoxys. Comparison with other palaeoscolecidans is relatively straightforward in terms of comparable examples in other Burgess Shale-type occurrences, but is much more tenuous with respect to the important record of isolated sclerites. These finds from Greenland provide further evidence that palaeoscolecidans possessed a complex anterior introvert directly comparable to a number of priapulid-like taxa from other Burgess Shale-type assemblages. Although these palaeoscolecidans have been allied with the nematomorphs, molecular data in conjunction with our observations suggest that this hypothesis is untenable. Palaeoscolecidans and similar priapulid-like taxa are probably primitive cycloneuralians and as such may indicate the original bodyplan of this important group of ecdysozoans. In addition, we describe another sclerite-bearing fossil from the Sirius Passet Fossil-Lagerstätte that may be related to the cambroclaves.

Key words: Palaeoscolecida, Chalazoscolex, Xystoscolex, Cycloneuralia, Cambrian, Kinzers Formation, Latham Shale, Sirius Passet, Greenland, California, Pennsylvania.

Simon Conway Morris [sc113@cam.ac.uk], Department of Earth Sciences, University of Cambridge, Downing Street, Cambridge, CB2 3EQ, England; John S.

Peel [john.peel@pal.uu.se] Department of Earth Sciences (Palaeobiology), Uppsala University, 
Villavägen 16, SE-752 36, Uppsala, Sweden.

This is an open-access article distributed under the terms of the Creative Commons Attribution License (for details please see creativecommons.org), which permits unrestricted use, distribution, and reproduction in any medium, provided the original author and source are credited.

Forif Full text $(2,627.9 \mathrm{kB})$ 